\title{
Effects of land use change on soil carbon cycle in process of urbanization in China
}

\author{
Liao Yan ${ }^{1, a}$, Wei Xiuju ${ }^{1, b^{*}}$ \\ ${ }^{1}$ Editorial Department of Transactions of the Chinese Society of Agricultural Engineering, \\ 41 Maizidian Street, Chaoyang District, Beijing 100125, China \\ aly_liaoyan@163.com, bweixj06@163.com
}

\begin{abstract}
Keywords: urbanization; land use change; soil; carbon cycle
Abstract: Urbanization is a target and result of economic development in China. Urbanization has changed the type of urban land use, and also affected the soil carbon cycle of urban ecosystem. In this paper, the land use change characteristics and soil carbon content in different land use types of urban ecosystem in the process of urbanization were reviewed, as well as the influence of urbanization on soil carbon characteristics, and the main factors affecting the carbon storage in urban surface soil. Finally, the future research direction of soil carbon cycle in urban ecosystem was discussed, and some countermeasures and suggestions were put forward to ensure soil carbon balance.
\end{abstract}

\section{Introduction}

Urbanization is a prominent phenomenon in contemporary China. Urbanization contains two aspects of contents, i.e. the transformation from rural areas to urban areas and the expansion of the existing urban areas. Urbanization in this paper mainly refers to the latter, and only the large cities' urbanization was reviewed and discussed [1-2]. Urbanization has changed the structure and function of urban ecosystem, and also changed the land cover type in cities and its surrounding areas [3-4].

The city area is strongly influenced by human activities [5-8], and the land use patterns show a high spatial and temporal variability, which directly changes the process of regional natural carbon cycle, and indirectly changes regional anthropogenic carbon emissions. Therefore, the study of soil carbon cycling in urban area has greater uncertainty and challenge [9-14].

There are relatively many studies on land use change in the process of urbanization. In addition to field sampling and model calculation, more and more "3S" technologies have been applied [15-21]. In these studies, the issue on how does the soil carbon cycle respond to the strong land use change in the process of urbanization is included [22-24]. This paper reviewed the influence of land use change on soil carbon cycle in China's urbanization process, aiming to provide reference for the study of carbon cycle in urban ecosystem.

\section{The characteristics of land use change in process of urbanization}

As the rural population gathers to the city, the scale of city continues to expand, and the city construction land, roads and other land area expand; and land use change is one of the external performances in the process of urbanization, which is strong and direct. In this process, the main feature of land cover change is the rapid expansion of construction land, which results in the decrease of forest land, arable land, garden plots and other areas, and the fragmentation of landscape [25].

The study found that during the years of 1992-2008, there was $792.69 \mathrm{~km}^{2}$ farmland changed to construction land in Beijing [26], urban construction land expanded with a decentralized group mode along the Ring Road (i.e. the main urban road with a circular shape in Beijing, e.g. the $2^{\text {nd }}$ Ring Road) outward, and a lot of cultivated lands were occupied [27]; in 2004-2013, the traffic land, and town and village and industrial land in Beijing City increased with an average annual growth rate of $8.089 \%$ and $1.29 \%$, respectively, and the arable land decreased with an average annual reduction rate of $0.73 \%$ [28]. In addition, as the figure showed, the built-up area in Beijing expanded from $1253 \mathrm{~km}^{2}$ in the year of 2000 to $2348 \mathrm{~km}^{2}$ in 2010 [29]. 


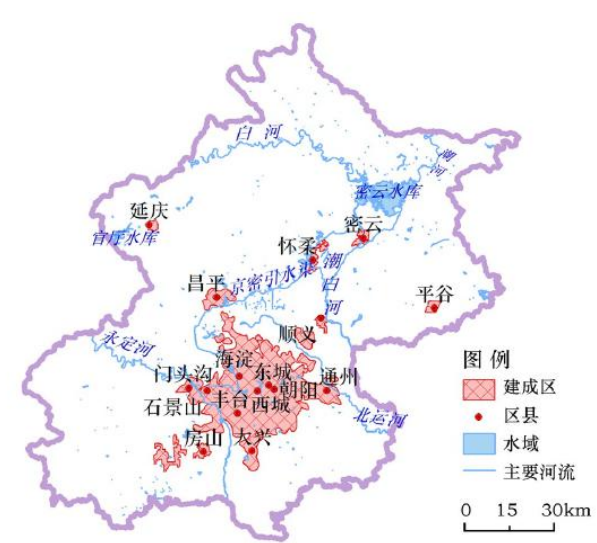

a. In the year of 2000

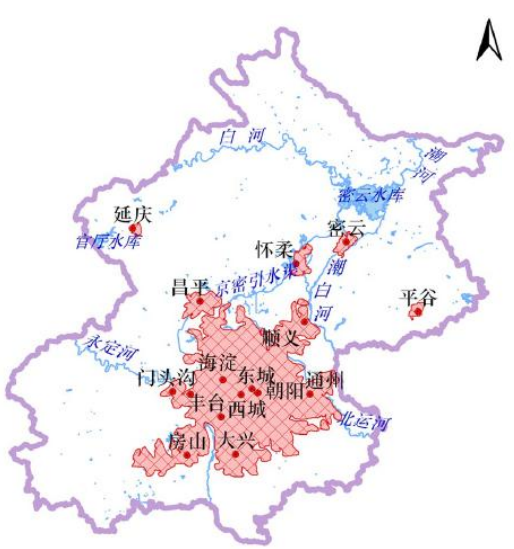

b. In the year of 2010

Figure Morphological changes of city space in Beijing from 2000 to 2010 [29]

In the process of urbanization, land use change also presents a feature of periodical change. Taking Shanghai as an example, as shown in the table [30], in the 3 periods, i.e. 1994-2000, 2000-2003 and 2003-2006, the farmland area in Shanghai continued to decrease; due to the acceleration of the process of urbanization further in 2000-2003, the annual average farmland reduced most significantly, and then the decrease trend slowed down obviously after 2003; the green area continued to increase, and the increase rate increased during the 2000-2003 period, followed by the slowing down of the growth rate; the industrial land, road traffic land and residential land were increasing consistently, and the growth rate continued to increase [30]. The built-up area of Shanghai in 1987-2008 grew at an average annual rate of $6.84 \%$, with an increase of $702 \mathrm{~km}^{2}$ by the year of 2008, and cultivated land area decreased with an average annual rate of $2.34 \%$ [26].

Table Statistics of annual area change of main land use types in Shanghai [30] (Unit: $\mathrm{hm}^{2} / \mathrm{a}$ )

\begin{tabular}{cccc}
\hline Land use type & Years of & Years of & Years of \\
& $1994-2000$ & $2000-2003$ & $2003-2006$ \\
\hline Farmland & -4624.92 & -13418.86 & -8667.21 \\
Green area & 421.94 & 1927.43 & 326.15 \\
Industrial & & & \\
land & 886.66 & 2939.74 & 5290.57 \\
Road and traffic land & 924.25 & 1212.88 & 2775.02 \\
Residential land & 459.38 & 1891.49 & 2516.8 \\
\hline
\end{tabular}

Note: minus indicates decrease

\section{Soil carbon content of different land use types in urban ecosystem}

In a typical urbanization area in the northwest suburbs of Beijing, the content of total carbon in soil changed between $0.918 \%$ and $2.546 \%$, the content of total carbon in urban forest land, artificial grassland and mountain forest land was relatively high, and that in bare land was the minimum, but the difference was not very significant [14]. The average soil organic carbon content at 0-30 cm depth was $0.72-40.52 \mathrm{~g} / \mathrm{kg}$ for different land use types in Shenzhen City, of which the mangrove was the highest, followed by the wetland and woodland; the soil organic carbon density ranged from 0.27 to $13.36 \mathrm{~kg} / \mathrm{m}^{2}$, and the construction and idle land showed a very low content and density of soil organic carbon [31]. The surface soil carbon density of the new development zone $\left(1.87 \mathrm{~kg} / \mathrm{m}^{2}\right)$ was significantly lower than that of the old urban area $\left(3.12 \mathrm{~kg} / \mathrm{m}^{2}\right)$ in Chongqing City; the soil carbon density of the regions with the slope of $2-6^{\circ}\left(3.36 \mathrm{~kg} / \mathrm{m}^{2}\right)$ and above $25^{\circ}\left(3.20 \mathrm{~kg} / \mathrm{m}^{2}\right)$ was relatively higher; among different green areas, the soil carbon density of green space of park and garden was the highest $\left(3.63 \mathrm{~kg} / \mathrm{m}^{2}\right)$, while the lowest value occurred in green area along roadside $\left(2 \mathrm{~kg} / \mathrm{m}^{2}\right)[32]$. The carbon sequestration capacity in paddy field was the highest among different land use patterns in Shanghai area, with the soil carbon density of $3.859 \mathrm{~kg} / \mathrm{m}^{2}$, the minimum was $1.379 \mathrm{~kg} / \mathrm{m}^{2}$ occurring 
in the intertidal zone, and the order for the soil carbon density of several other land use patterns was: dry land $>$ forest land $>$ abandoned land $>$ city lawn $>$ garden plot [30].

\section{The influence of urbanization on soil carbon characteristics}

For the functional areas with different degrees of urbanization in Beijing, the soil organic carbon content was relatively high in the new urban development zone and the ecological conservation area with relatively low degree of urbanization, and was low in the capital core functional area and the city functional expansion area, which has a relative high degree of urbanization and stronger human disturbance. And the development speed of urbanization was approximately negatively correlated with the organic carbon content and carbon-nitrogen ratio [33]. During the rapid urbanization process in 1987-2007, the vegetation and soil carbon storage in Shanghai City decreased from $4.1 \times 10^{7}$ to $3.2 \times 10^{7} \mathrm{t}$, the total reserves decreased by $0.9 \times 10^{7} \mathrm{t}$, and the negative effect of urbanization level on carbon reserves was significant [34]; the surface soil organic carbon loss was about $4.23 \times 10^{6} \mathrm{t}$, and the soil organic carbon loss per unit area was even larger in the expansion area within the period of 1999-2007 [35]. Shenzhen is one of the cities with the fastest urbanization in China; in the initial stage, accelerated stage and stable stage in the urbanization process, the carbon storage in urban ecosystem roughly corresponded to the high carbon storage period mainly owing to natural vegetation and agricultural land, the rapid decrease period of carbon storage due to the rapid expansion of construction land, and the carbon reserves gradual recovery period [25]. During the years of 1998-2005, the urbanization process in Zhengzhou eroded the suburban green space, resulting in a rapid decline in the carbon storage capacity of the agricultural ecosystem in the suburbs [36].

Generally speaking, in the urbanization process, there will be a lot of farmland occupied and then transformed into construction land, road land, and so on. Original accumulation way of soil organic carbon is cut off, so the surface soil organic carbon density and storage will be significantly reduced, which is a typical characteristic of urbanization process. The urbanization process of different typical cities has changed the land use pattern, and also changed the surface soil properties, thus changing the characteristics of soil carbon.

\section{Main influencing factors of urban surface soil carbon storage}

The carbon storage and its spatial distribution of urban surface soil are affected by soil physical and chemical properties, environmental factors and human factors [37]. Soil physicochemical properties include soil nitrogen content, $\mathrm{pH}$ value, bulk density, and so on; environmental factors include the distance from city center, greenbelt type, urban and suburban difference, urban expansion period and slope; among the effects of human activities, the good management and protection, and the arbor-shrub-grass composite configuration are conducive to carbon accumulated [32,37]. The research found that the organic carbon, inorganic carbon and total carbon content in the soil of typical green area in Beijing had the significant positive correlation with the built time of green area; the holding rates of 3 kinds of carbon in green space of residential area were respectively 46, 19 and 65 $\mathrm{g} /\left(\mathrm{m}^{2} \cdot \mathrm{a}\right)$, showing a trend of increasing linearly with the built time, but the soil carbon accumulation in park green space was influenced greatly and relatively low due to human disturbance, such as landscape transformation [37].

In the process of urbanization, land use changes significantly, which then affects the surface carbon cycle process. This relationship can be showed from the 2 aspects: on one hand, some processes, including non-agricultural conversion of land use, land development, and land use intensification, will increase the disturbance of the soil carbon pool, accelerate the decomposition of soil carbon, and increase carbon emissions; on the other hand, the land use change, such as afforestation, returning farmland to forests and grassland, and disintensification of agricultural land use, can reduce carbon emissions and increase carbon sequestration [38]. 


\section{Suggestions and perspectives}

In the context of global change, with the economic development, urbanization has become one of the most important social and economic phenomena in the world. The development of urbanization is one of the goals of economic development in China, and the urbanization has resulted in a reduction in carbon density and storage of urban ecosystem, but through appropriate vegetation and soil carbon management measures, the carbon pool in urban ecosystem can be recovered gradually [25]. Reasonable land management measures can improve soil carbon sequestration potential. The research shows that increasing the application of green manure, increasing the proportion of straw incorporated, and combining the application of organic fertilizer and chemical fertilizer, can make the carbon-fixed potential of farmland soil increase obviously; afforestation has an obvious effect on forest vegetation and soil carbon sequestration; strengthening the construction of urban green space, and improving the management level of urban green space, also play an important role in increasing soil carbon sequestration in cities [30].

In the present study, there is lack of dynamic data of soil carbon density with time change under different land use types in the process of urbanization [39]. For the research method, either model estimation or remote sensing estimation, field sampling, there are large uncertainties [40-41]. In addition, it is still difficult to quantitatively determine the different factors that affect the carbon dynamics of urban ecological system and their interaction [42].

\section{References}

[1] T. Yaohua: Concept research of urbanization and new definition, submitted to Academic Forum, 36(5):113-116 (2013)

[2] S. Pingjun, L. Fei, X. Chunliang and X. Cunxu: Basic cognition and evaluation of urban economical and intensive land use under the new urbanization, submitted to Economic Geography, 35(8):178-183 (2015)

[3] S.M. Raciti, L.R. Hutyra and J.D. Newell: Mapping carbon storage in urban trees with multi-source remote sensing data: Relationships between biomass, land use, and demographics in Boston neighborhoods, submitted to Science of the Total Environment, 500-501: 72-83 (2014)

[4] Y. Yangfan, J. Pingbin and Z. Xinyu: Change of land use in process of urbanization in Hangzhou during past 30 years, submitted to Journal of Zhejiang University (Engineering Science), 51(7): 1462-1474 (2017)

[5] X. Naizheng, Z. Taolin, W. Xingxiang and L. Hongying: Analysis on evolution trend of soil organic carbon stock during the course of urbanization, submitted to Chinese Journal of Soil Science, 3: 659-663 (2011)

[6] S. Brown, E. Miltner and C. Cogger: Carbon sequestration potential in urban soils, submitted to Carbon Sequestration in Urban Ecosystem, 173-196 (2012)

[7] S.L. Robinson, J.T. Lundholm: Ecosystem services provided by urban spontaneous vegetation, submitted to Urban Ecosystems, 15(3): 545-557 (2012)

[8] H. Yanping, C. Weisong, X. Sulin and Z. Hongda: Influence of land use and land cover changes on characteristics of soil total carbon and total nitrogen of Nantai Island in Fuzhou City, submitted to Urban Environment \& Urban Ecology, 28(5): 1-7 (2015)

[9] W. Meng, R. Li and C. Yinrong: Simulation of urban land use carbon emission system based on a system dynamic model: Take Wuhan as an example, submitted to China Land Science, 31(2): 29-39 (2017)

[10] H. Chenxia, G. Xudong, L. Gang and Z. Zhongming: Effects of land use change on ecosystem service value in rapid urbanization areas in Yangtze River Delta: A case study of Jiaxing City, submitted to Resources and Environment in the Yangtze Basin, 26(3): 333-340 (2017)

[11] M. Dandan: Research on carbon emission effect of land us and its optimization in the rapid urbanized areas: A case study in typical cities in Shandong (Liaocheng University, 2015) 
[12] L.R. Hutyra, B. Yoon, J. Hepinstall-Cymerman, and M. Alberti: Carbon consequences of land cover change and expansion of urban lands: A case study in the Seattle metropolitan region, submitted to Landscape and Urban Planning, 103(1): 83-93 (2011)

[13] L. Feng, Y. Yaping, S. Bowen and W. Rusong: Spatial structure of urban ecological land and its dynamic development of ecosystem services: A case study in Changzhou City, China, submitted to Acta Ecologica Sinica, 31(19): 5623-5631 (2011)

[14] Z. Tinglong, S. Rui, H. Bo, D. Yinuo and S. Liang: Analyzing soil carbon characteristics of typical urbanization zones in northwestern Beijing, submitted to Journal of Beijing Normal University (Natural Science), 46(1): 97-102 (2010)

[15] M. Nkambwe and W. Arnberg: Monitoring land use change in an African tribal village on the rural-urban fringe, submitted to Applied Geography, 16(4): 305-317 (1996)

[16] A.I.R. Cabral and F.L. Costa: Land cover changes and landscape pattern dynamics in Senegal and Guinea Bissau borderland, submitted to Applied Geography, 82: 115-128 (2017)

[17] C.N. Thomson and P. Hardin: Remote sensing/GIS integration to identify potential low-income housing sites, submitted to Cities, 17(2): 97-109 (2000)

[18] K.R. Dahal, S. Benner and E. Lindquist: Analyzing spatiotemporal patterns of urbanization in Treasure Valley, Idaho, USA, submitted to Applied Spatial Analysis \& Policy, 1-22 (2016)

[19] Z.Y. Yin, D.J. Stewart, S. Bullard and J.T. Maclachlan: Changes in urban built-up surface and population distribution patterns during 1986-1999: A case study of Cairo, Egypt, submitted to Computers Environment \& Urban Systems, 29(5): 595-616 (2005)

[20] F. Aguilera, L.M. Valenzuela and A. Botequilha-Leitão: Landscape metrics in the analysis of urban land use patterns: A case study in a Spanish metropolitan area, submitted to Landscape \& Urban Planning, 99(3): 226-238 (2011)

[21] G. Li, Y. Lei, H. Yao, S. Wu and J. Ge: The influence of land urbanization on landslides: An empirical estimation based on Chinese provincial panel data, submitted to Science of the Total Environment, 595(1): 681-690 (2017)

[22] R. Pouyat, P. Groffman, I. Yesilonis and L. Hernandez: Soil carbon pools and fluxes in urban ecosystems, submitted to Environmental pollution, 116(S1): 107-118 (2002)

[23] K. Lorenz and E. Kandeler: Biochemical characterization of urban soil profiles from Stuttgart, Germany, submitted to Soil Biology and Biochemistry, 37(7):1373-1385 (2005)

[24] P. Jie, W. Li, C. Ziwei, F. Qinghua and N. Zheng: Land Use/Cover Change and carbon effect in Shenzhen City based on RS and GIS, submitted to Research of Soil and Water Conservation, 24(3): 227-233 (2017)

[25] Y. Juantao, W. Jun, L. Shunzi and Z. Hui: Impacts of rapid urbanization on carbon dynamics of urban ecosystems in Shenzhen, submitted to Ecology and Environmental Sciences, 26(4): 553-560 (2017)

[26] M. Lijuan, C. Xuefeng, L. Yibo and H. Bin: Similarities and differences of Beijing and Shanghai's land use changes induced by urbanization, submitted to Scientia Meteorologica Sinica, 31(4):398-404 (2011)

[27] Z. Youquan, G. Huili, Z. Wenji and L. Xiaojuan: Analyzing the mechanism of land use change in beijing city from 1990 to 2000, submitted to Resources Science, 29(3): 206-213 (2007)

[28] J. Yingyan: Research on land use change in the process of urbanization in Beijing (Capital University of Economics and Business, 2015)

[29] X. Gaodi, Z. Biao, L. Chunxia, X. Yu, L. Chunlan, Z. Bo, X. Qian, L. Lingjun and C. Zhiping: Rapid expansion of the metropolitan areas and impacts of resources and the environment, submitted to Resources Science, 37(6):1108-1114 (2015)

[30] S. Lijiang: Research on land use change and soil carbon pool in Shanghai based on remote sensing and GIS (East China Normal University, 2009)

[31] L. Weiling, Z. Linbo, Y. Youhua, Z. Jianfeng, W. Yizhe and Q. Yue: Content and density of soil organic carbon under different land use types in Shenzhen, submitted to Ecological Science, 30(5): 486-492 (2011) 
[32] L. Yong, W. Cheng, Y. Wenze, C. En, L. Jin and H. Yanyan: The characteristics of soil organic carbon density and storage in urban Chongqing, submitted to Sciencepaper Online (2012)

[33] S. Mimi, L. Qiuxi and W. Mingzhu: Effect of rapid urbanization in Beijing area on soil carbon and nitrogen characteristics, submitted to Modern Horticulture, 16: 12-13 (2013)

[34] A. Youzhi and Z. Qingjun. Impact of rapid urbanization on temporal and spatial variation of shanghai vegetation and soil carbon storage, submitted to Environmental Science and Management, 41(8): 152-155 (2016)

[35] Z. Rui, P. Xianzhang, X. Xianli, W. Baoliang, W. Changkun, L. Ya and L. Yanli: Urbanization and its impact on organic carbon storage in topsoil--taking shanghai as a case study, submitted to Chinese Journal of Soil Science, 5: 1163-1167 (2013)

[36] H. Li, Y. Junfeng and W. Mingzuo: Analysis on carbon reserve of soil and plant in city: A case study in Zhengzhou, in the annual meeting of the association of Chinese (2008)

[37] L. Shanghua: Research on the effect of rapid urbanization on urban surface soil carbon pool in Beijing (University of Chinese Academy of Sciences, 2014)

[38] Y. Qingyuan: Land use changes and the carbon cycling, submitted to China Land Science, 24(10):7-12 (2010)

[39] D.G. Brown, D.T. Robinson, N.H.F. French and B.C. Reed: Land use and the carbon cycle advances in integrated science management and policy[M]. England: Cambridge University Press: 305-324 (2013)

[40] Y. Yan, Z. Chi, H. Yunfeng and K. Wenhui: Urban land-cover change and its impact on the ecosystem carbon storage in a dryland city, submitted to Remote Sensing, 8(1): 6 (2015)

[41] C. Zhang, H.Q. Tian, G.S. Chen, A. Chappelka, X. Xu, W. Ren, D. Hui, M. Liu, C. Lu, S. Pan and G. Lockaby: Impacts of urbanization on carbon balance in terrestrial ecosystems of the Southern United States, submitted to Environmental Pollution, 164(5): 89-101 (2012)

[42] C. Zhang, H.Q. Tian, S. Pan, G. Lockaby and A. Chappelka: Multi-factor controls on terrestrial carbon dynamics in urbanized areas, submitted to Biogeosciences, 11(24): 7107-7124 (2014) 